\title{
AS REFORMAS NEOLIBERAIS E SUAS INFLUÊNCIAS NA POLÍTICA DE EDUCAÇÃO ESPECIAL DO BRASIL E DA VENEZUELA: EXPLICITANDO RESULTADOS E MUDANÇAS A PARTIR DOS GOVERNOS DE LULA E CHÁVEZ
}

\author{
Vandiana Borba Wilhelm ${ }^{1}$ \\ SEED/PR \\ Francis Mary Guimarães Nogueira ${ }^{2}$ \\ UNIOESTE
}

\begin{abstract}
RESUMO
O presente artigo tem por objetivo explicitar alguns contrastes e semelhanças da trajetória histórica e conceitual da política de educação especial do Brasil e da Venezuela. Todavia coerente ao referencial marxista, essa modalidade da educação escolar não pode ser analisada descolada das relações sociais que a produziram, desse modo, principiamos por expor alguns elementos da reforma neoliberal, as quais expressam as alterações da base material, política e cultural da América Latina em geral, para posteriormente articulá-las às reformas educacionais da década de 1990 nos países supra citados, buscando destacar as influências dessa reforma na particularidade da política de educação especial, bem como algumas mudanças desencadeadas a partir da gestão do presidente Luis Inácio Lula da Silva e Hugo Rafael Chávez Frías, sendo o principal resultado o aumento significativo do acesso à educação formal por parte de pessoas com deficiência.

Palavras-chave: Reformas neoliberais; Política educacional; Pessoas com deficiência; Brasil e Venezuela.
\end{abstract}

\section{THE NEO-LIBERAL REFORMS AND THEIR INFLUENCES ON SPECIAL EDUCATION POLICY OF BRAZIL AND VENEZUELA: EXPRESSING RESULTS AND CHANGES FROM GOVERNMENTS OF LULA AND CHÁVEZ}

\section{ABSTRACT}

The present article aims to explain some contrasts and similarities of conceptual and historical background of special education policy of Brazil and Venezuela. However coherent to the Marxist reference line, this type of schooling cannot be analyzed separately from social relations that produced it, this way, We begin exposing some elements of the neoliberal reform, Which express the changes of the base material, political and cultural life of Latin America in general, and later link them to the educational reforms of the 1990 s in the countries mentioned above, seeking to highlight the influences of this particular policy reform in special education, as some changes that have been triggered from the administration of President Luis Inácio Lula da Silva and Hugo Rafael Chavez Frias, being the main result of the significant increase in access to formal education for people with disabilities.

Keywords: Neoliberal reforms; Educational policy; People with disabilities; Brazil and Venezuela. 


\section{Introdução}

A partir de análises documentais, no presente artigo objetivamos comparar determinados contrastes e semelhanças da política de educação especial entre Brasil e República Bolivariana da Venezuela, em relação aos aspectos concernentes à trajetória histórica, conceitual e os resultados concretos da implementação dessa política, os quais estão expressos nos indicadores numéricos de matrículas.

Antes, porém, de iniciarmos essa discussão, entende-se que a política de educação especial é parte integrante das políticas educacionais como um todo, e que esta, por sua vez, não possui um caráter autônomo e muito menos hegemônico, desse modo, de acordo com orientação teórico-metodológica, esta política de estado não poderia ser analisada a não ser nas relações sociais que dão origem a mesma. Sobretudo, porque as alterações na base material, de forma mediatizada, incidem no campo educacional, onde emergem novas contradições. Nesse contexto, vale explicar que não são somente aquelas contradições da base material, pois este artigo expõe inicialmente, de forma sumária, alguns dados teóricos e históricos das reformas neoliberais, para estabelecer os nexos desta reforma, com a temática central deste trabalho.

Dito isto, principiamos por pontuar e problematizar sobre alguns elementos da reforma neoliberal desencadeada nos países centrais ${ }^{3}$, para posteriormente, discorrermos sobre as repercussões oriundas dessas reformas no cenário latino americano em geral, e em particular, no Brasil e na Venezuela. Tecida essa fundamentação, passaremos então a análise das determinações mediatizadas das reformas neoliberais no campo educacional, para em seguida, articularmos essa discussão à política de educação especial nos países foco desse artigo.

\section{As reformas neoliberais e suas repercussões na América Latina}

Para abordar a temática desse subtítulo, vale assinalar que as raízes teóricas, ideológicas e políticas do programa de dominação econômica do capital elaborado no decorrer da Segunda Guerra Mundial, denominado por neoliberalismo, podem ser localizadas nos postulados do economista austríaco Friedrich August von Hayek (18991992, e de outros expoentes que opunham-se as denominadas políticas keynesianas concretizadas no pós segunda guerra.

Os princípios neoliberais formulados na década de 1940 rejuvenescem e se atualizam a partir da crise econômica Da década de 1970, a qual foi decisiva para o definhamento do regime de acumulação fordista e para a reorganização do capitalismo sob novas bases produtivas, ou seja, o regime de acumulação flexível, com isto produzindo alterações na base material e ao mesmo tempo, acarretando implicações nas demais esferas do campo político e cultural.

Face ao disposto, convém assinalar que o neoliberalismo tem seu berço em décadas passadas, todavia, é nos anos de 1980 e 1990 que este pensamento político e econômico encontrou-se em uma fase de consolidação, propagação e intensas reformas, principalmente nos países periféricos. Desse modo, cabe salientar que o neoliberalismo nesse momento histórico apresentou-se como outra fase do capital e, portanto, em diferentes bases materiais, políticas e culturais. Entretanto, continuou seguindo os mesmos princípios do velho liberalismo do século XVIII, onde, desde esse período, a igualdade, a 
liberdade, a individualidade, a propriedade e a democracia são diuturnamente reafirmadas e fortalecidas.

O receituário neoliberal nos países centrais e nos países periféricos latinoamericanos, onde destacamos o Brasil e a Venezuela, não penetrou de forma idêntica, pois se nos países em questão, as políticas neoliberais enraizaram-se no final da década de 1980, no Chile, durante a ditadura de Pinochet, encontrou um terreno fértil para emergir.

De modo geral, a abertura para as reformas neoliberais concentram-se no ano de 1982, data conhecida como o ponto de eclosão Do endividamento externo, crise que já vinha como processo desde o final da década de 1970, podendo ser caracterizada como a transferência da crise dos países centrais para os periféricos, o que corroborou para o aceleramento do processo de anuência as reformas neoliberais, sendo elas aprofundadas no final dessa mesma década e no decorrer dos anos de 1990, com a adesão irrestrita, mas com intensidade diferente dos países periféricos, às diretrizes contidas no Consenso de Washington.

No rastro da crise econômica e política, os empréstimos para ajuste estrutural negociados com os organismos financiadores multilaterais, colocaram-se como condicionalidades para a renegociação da dívida externa e forma de cobrar dos países endividados maior rigor fiscal, a exemplo da redefinição do papel do Estado, feito que atingiu as instâncias e instituições que o constituem, como a escola, que historicamente foi chamada a atender as novas demandas do capitalismo.

Foi por esse caminho que o neoliberalismo se desenvolveu no continente latinoamericano, aprofundando a pobreza e agravando os problemas sociais. Por essas latitudes, as particularidades do neoliberalismo se direcionaram para a adaptação às exigências do grande capital internacional, na manutenção do papel de exportadores de matéria-prima, na conservação da condição de subordinação às economias e política aos países centrais, assim como a abertura dos mercados nacionais. Todavia, de acordo com a observação de Boito (1999, p. 49), "O imperialismo não é apenas uma força externa às nações periféricas. Ele sempre entrelaçou seus interesses com classes e frações de classe dos próprios países dominados". Ou seja, a situação de dependência não se deu tão somente por imposições, mas, também, por convenções firmadas com as elites nacionais dirigentes, que amealham uma parte menor da mais valia.

Exposto alguns elementos concernentes às reformas neoliberais que trouxeram alterações na base material e em todas as instâncias sociais e culturais, queremos destacar a "sentença" ideológica sustentada pelos velhos liberais e pelos neoliberais de que a educação é o motor para o desenvolvimento econômico, devendo cumprir seu atributo, isto é o de dar formação ao novo homem, uma formação compatível com as alterações e as exigências do mundo produtivo, agora em sua versão flexível, para continuar a essência imutável, da acumulação, reprodução e concentração de capital.

Com a certeza de que o acesso ao mundo letrado gera novas necessidades que estão condicionadas ao consumo de mercadorias, ao aumento da produtividade, dentre outros fatores, a educação ergueu-se como alavanca para a solução dos problemas sociais, além de colocar-se como requisito para o ingresso ao mundo globalizado e meio de incorporação dos novos códigos da modernidade. ${ }^{4}$

Nessa perspectiva, em consonância com Nagel (2001),

[...] impossível pensar a educação sem pensar nas alterações da base produtiva, nas exigências de reorganização do capital, sempre explicitadas pela constante modernização do sistema. Nesse sentido, impossível pensar a educação fora do espectro da contradição que põe lado a lado a mudança e a permanência, que impõe novas formas de 
trabalho no interior da mesma relação de produção, que aciona velhas atitudes, apenas maquiadas pelo velho dogma do mercado. (2001, p. 101).

A referência acima explica porque a exposição deste artigo inicia partindo de dados sumários das reformas neoliberais. Apresentamos a partir desse momento, as particularidades da emergência e forma de difusão do neoliberalismo do Brasil e da Venezuela e a inflexão destas políticas econômicas para a política de educação especial.

No Brasil, em termos de marco decisório e de implementação decisiva das receitas do Consenso de Washington, destacamos a gestão do ex-presidente da República Fernando Collor de Melo (1990 -1992), o qual segundo Batista (2001) principiou a liberalização comercial e financeira com a abertura unilateral do mercado brasileiro em nome da inserção ao mundo globalizado; a ofensiva às privatizações dos bens públicos, e dentre outras medidas que impactou negativamente as condições de vida e da organização dos trabalhadores.

Essas ações políticas foram aprofundadas no decorrer das duas gestões do expresidente Fernando Henrique Cardoso (FHC 1995-1998 e 1999-2002), dando ênfase À reforma do Plano Diretor da Reforma Administrativa do Aparelho do Estado, À intensificação das privatizações do patrimônio público, a precarização da força de trabalho, a redução dos gastos sociais e a supressão dos direitos sociais, medidas estas que explicitam a adesão aos princípios neoliberais que já estavam aparentemente consolidados nos países centrais, a exemplo da desregulamentação, da disciplina fiscal, da priorização dos gastos públicos e da liberalização financeira e comercial. Cabe destacar ainda que com a crise do capitalismo internacional que explodiu no final de 2008 nos Estados Unidos da América, espalhando-se para toda a Europa, demonstra que a crise fiscal da Grécia, da Irlanda, da Espanha e de Portugal evidenciam que parte do receituário neoliberal não foi cumprido, e agora os trabalhadores estão sofrendo o revés do neoliberalismo e a "mão de ferro" do estado burguês.

Na sociedade venezuelana, trazemos como marco de emergência do neoliberalismo a gestão do ex-presidente Carlos Andrés Pérez (1989-1993), que foi o responsável por firmar com o Fundo Monetário Internacional (FMI), nos primeiros dias de seu governo, em 1989, o que ficou conhecido como "o pacote", ou seja, um conjunto de medidas que faziam parte dos ajustes estruturais pelos quais diferentes países da América Latina estavam sendo condicionados.

Essas reformas agravaram a pobreza no país, sendo ainda mais intensificadas na gestão do ex-presidente Rafael Caldera, que, em 1996, desencadeou novas reformas, denominadas "Agenda Venezuela", colocando em prática ações que visavam à redução dos gastos sociais, à abertura do setor petroleiro ao capital internacional, à privatização de empresas estatais, dentre outras medidas que aprofundaram e ampliaram o contingente de pobres no país.

Especificamente sobre as reformas educacionais, ressaltamos a elaboração e a difusão de diversos documentos internacionais que foram norteadores dessas reformas nos países periféricos, a exemplo do documento oriundo da Conferência Mundial de Educação para Todos --"Satisfação das necessidades básicas de aprendizagem", realizada em Jomtien, Tailândia, no ano de 1990, cujo teor centrou-se na defesa da universalização da Educação Básica ${ }^{5}$ e na erradicação do analfabetismo.

Além deste, destacamos também o documento econômico da CEPAL, "Transformação Produtiva com Equidade" (1990) e o de 1992, intitulado "Educação e Conhecimento: eixo da transformação produtiva com equidade". Nesse ângulo, mencionamos também o relatório organizado por Jacques Delors entre 1993 e 1996, 
encomendado pela UNESCO e intitulado "Educação, um tesouro a descobrir", dentre outros.

Em âmbito brasileiro, das metas a serem atingidas por meio da reforma educacional, nossa referência ficará restrita à universalização do ensino fundamental, meta esta que sustentou política e ideologicamente o discurso de que a inserção na escola regular de grupos marginalizados, dentre os quais localizamos as pessoas com deficiência, público da política de educação especial, era um imperativo do chamado mundo globalizado, fomentando, dessa forma, a idéia da inclusão educacional de todos. Este discurso corroborou para o processo de universalização desse nível de ensino, resultado que foi divulgado no ano de 2001 com base no Censo de 2000, ao ser atingido o índice de ingresso de $96,3 \%$ das crianças em idade escolar.

Sobre a meta da universalização do ensino fundamental, Nogueira (2001), alerta para o fato de que os documentos internacionais, em consonância com o Banco Mundial, que tem na educação o motor para o desenvolvimento econômico e a contenção da pobreza, financiando projetos e elaborando diretrizes, a exemplo da busca por novas fontes de financiamento, sem dúvida, balizaram as reformas educacionais desencadeadas na década de 1990. Entretanto, essas reformas não se constituíram tão somente de recomendações internacionais, mas, também, de ações de âmbito nacional que vieram ao encontro delas, produzindo um consenso em torno da centralidade da educação básica.

A referida autora apresenta um panorama geral da origem e concomitância destas políticas internacionais, partindo de medidas governamentais que antecederam a Conferência de Jomtien e de outras que, posteriormente, se entrelaçaram a ela e culminaram com a efetivação da universalização do ensino fundamental no ano de 2001. Segundo Nogueira (2001),

O consenso em torno da Centralidade da Educação Básica não foi um projeto interventor, "maquiavélico" e unívoco do Banco Mundial para a sociedade e para a educação brasileira. Nos anos 80 , ao mesmo tempo que se definia, se propunha e se financiava políticas econômicas, culturais e educacionais de forma insistente pelo Banco Mundial e outros Organismos Internacionais Multilaterais, se elaborava em nível nacional através de Governos Estaduais e Municipais, políticas educacionais que combatiam a evasão e a repetência. Num outro plano, emergiam também reivindicações com essa mesma temática de associações acadêmicas, de movimentos sindicais de todos os níveis de ensino, de estudantes e de movimentos populares que entendiam que a luta pela escola pública era a luta por melhores condições de vida para seus filhos. (2001, p. 21).

\section{A política de educação especial no Brasil}

Delineado esse panorama, sublinhamos que no bojo das reformas educacionais da década de 1990 que o tema da inclusão educacional de pessoas com deficiência em escolas da rede regular de ensino adquire ênfase, apesar de que, o conceito de inclusão e a escolarização desse segmento social em escolas ditas comuns não é uma originalidade dessa década ${ }^{6}$, todavia, é nesse momento histórico que se propaga e ganha novos contornos. Cabe assinalar também que antes da difusão do conceito inclusão, na trajetória histórica da constituição da educação especial brasileira enquanto uma política de Estado, dois outros conceitos Já estavam presentes, sendo eles o da institucionalização e o da integração, mudanças conceituais estas que não transcorreram de forma linear, e que apesar 
dos anos que os separam em termos de marco histórico, não houve rupturas paradigmáticas, pois na atualidade, a existência de concepções e práticas ainda os mantém no cenário da política educacional.

Na sequência, buscaremos definir sumariamente esses três modelos educacionais, trazendo algumas informações e os resultados concretos da política de educação especial, mais especificamente, da escolarização de pessoas com deficiência no Brasil, para posteriormente, expor alguns contrastes e semelhanças dessa política educacional em âmbito venezuelano.

Em relação à institucionalização, esclarecemos que este é um modelo de atendimento iniciado ainda na Idade Média, por meio do confinamento daqueles desviantes da norma, ou que não davam conta de prover sua subsistência, em asilos e em outras instituições segregadoras, como os hospitais psiquiátricos. No capitalismo, essa prática tem continuidade por intermédio da criação dos institutos para a educação de cegos e surdos na Europa, Na segunda metade do século XVIII, sendo que no Brasil, o primeiro instituto é datado do ano de 1854, constituindo-se no marco inicial da educação especial brasileira.

É pertinente parafrazearmos Bueno (1993), o qual salienta que embora os institutos portassem o timbre de locus para o processo ensino-aprendizagem, por décadas a instrução formal foi secundarizada, e as escolas/institutos tornaram-se uma espécie de asilo-oficina, lembrando que, para essas instituições, eram enviadas pessoas com deficiência pertencentes à classe pobre.

No Brasil, somente por volta de 1960 é que esse modelo filantrópico-assistencial pautado na institucionalização passou a ser contestado e visto como uma afronta aos direitos humanos, assim como a ser objeto de estudos e de publicações acadêmicas. Desse modo, em meio ao debate que se instaurava, dois novos conceitos emergiram, sendo eles o da normalização e o da desinstitucionalização. A normalização partia do princípio de que, para introduzir a pessoa com deficiência na sociedade, a pessoa necessitava adquirir as condições e os padrões da vida cotidiana, no nível mais próximo possível do normal. Assim, os serviços destinados a esse fim foram ofertados em escolas especiais, nas entidades assistenciais e nos centros de reabilitação. Dessa forma,

Ao se afastar do Paradigma da Institucionalização e adotar as idéias de Normalização, criou-se o conceito de integração, que se referia à necessidade de modificar a pessoa com necessidades educacionais especiais, de forma que esta pudesse vir a se assemelhar, o mais possível, aos demais cidadãos, para então poder ser inserida, integrada, ao convívio em sociedade. (BRASIL, 2000, p. 16).

Com base na citação acima, identificamos que o modelo da integração que passou a nortear a educação especial brasileira, contrapondo-se à institucionalização, embora mais evoluído, em última instância, também desaguava na segregação ao atribuir a responsabilidade pela adaptação e pela inserção social ao indivíduo, sem que questões mais amplas, tais como as barreiras de ordem arquitetônica e barreiras atitudinais e outras formas de adaptações fossem pensadas no conjunto do processo de integração social. Desse modo, se mesmo passando pelos serviços voltados à normalização, o indivíduo fosse julgado inapto, aqui em particular à educação, a plena integração escolar não se consolidaria e a formação educacional prosseguiria nos institutos, os quais resistiram à mudança conceitual, como nas escolas de educação especial Pestalozzi e APAEs, que se expandiram, assim como nas classes especiais.

Nesse percurso, é relevante destacar também que é em meio ao movimento da integração que no ano de 1973 é criado o Centro Nacional de Educação Especial 
(CENESP, hoje Secretaria de Educação Especial-SEESP), órgão vinculado ao Ministério da Educação para pensar a política nacional de educação especial, sendo somente nesse momento que a educação de pessoas com deficiência passa a ser uma política de Estado.

O modelo educacional pautado na integração trazia a orientação para a inserção na escola regular, entretanto era uma inserção parcial e condicionada ao nível de adaptação do aluno. Essa foi a razão pela qual, já no final dos anos de 1980, que o modelo da integração também enfrentou críticas, tendo em vista a insuficiência de seus resultados frente à avaliação de organismos internacionais, como a UNESCO, e também das próprias pessoas com deficiência, que, já organizadas em associações ou em outras instâncias de representatividade, reivindicavam a plena participação social e o acesso a todos os espaços da sociedade, dentre eles, a escola, espaços estes que deveriam estar adaptados para atender suas necessidades, ao invés destas, individualmente, terem que se adaptar a um meio que não lhes oferecia condições favoráveis.

Essas reivindicações vieram ao encontro do conceito de inclusão que começava a ser difundido na esfera governamental, respaldadas por recomendações de documentos internacionais, gerando intensos debates principalmente no campo educacional. Nesse percurso, o direito ao acesso à escola regular por parte de pessoas com deficiência foi se fazendo presente no arsenal legislativo, o qual embora limitado, e muitas vezes restrito ao plano formal, pode ser tomado como um instrumento válido para o enfrentamento político, para a denúncia do não cumprimento pleno e para o acirramento das contradições.

Legalmente, é no ano de 2001 com a aprovação da Resolução CNE/CEB n ${ }^{\circ}$ 2, que institui as Diretrizes Nacionais para a Educação Especial na Educação Básica, que o conceito de inclusão, ainda de forma pouco elaborado, constou na legislação, embora desde o ano de 1994, com a publicação do documento internacional intitulado Declaração de Salamanca ${ }^{7}$--"Sobre Princípios, Política e Prática em Educação Especial", esse conceito tenha sido divulgado, trazendo a equivocada ideia de que a inclusão educacional era uma originalidade dos anos de 1990.

Já na gestão do presidente Luiz Inácio Lula da Silva (2003-2006 e 2007-2010), a política de educação especial vai adquirindo novos contornos, podendo-se destacar a institucionalização do "Programa Educação Inclusiva: direito à diversidade", que teve início no ano de 2003 tendo por objetivo contribuir na política de construção de escolas inclusivas em todo o país.

Podemos dizer que o ano de 2008 é o ano em que o conceito inclusão educacional se faz presente na legislação deforma mais definida, e para essa afirmação, fazemos menção à aprovação da "Política Nacional da Educação Especial na Perspectiva da Educação Inclusiva", publicada em janeiro de 2008. Essa política está em consonância com o Parecer CNE/CEB n ${ }^{\circ} 13$, homologado pelo Ministro da Educação, Fernando Haddad, em 23 de setembro de 2009, que trata das diretrizes operacionais para o atendimento educacional especializado para os alunos com deficiência, transtornos globais do desenvolvimento e altas habilidades ou superdotação, orientando a matrícula desses alunos em classes regulares e no atendimento educacional especializado.

Resumidamente, a orientação da Secretaria da Educação Especial é a inclusão educacional de todas as pessoas com deficiência em classes comuns do ensino regular e a transformação das escolas de educação especial em centros de atendimento educacional especializado, bem como a implantação das salas de recursos multifuncionais ${ }^{8}$ em âmbito nacional, o que já vinha ocorrendo gradativamente desde o ano de 2005, sendo que este atendimento não pode ser substitutivo à escolarização regular, diferença central em relação à Resolução 2/2001. 
Ainda recente, o teor dessa política da educação especial tem provocado intensos debates e reações acadêmicas e políticas das mais diversas, sendo que, estando em fase de desdobramentos e de tentativas de implantação, é um objeto difícil para sobre ele se fazer afirmações categóricas ou confirmações analíticas. Desse modo, sem a pretensão de aprofundarmos a discussão, o objetivo de fazermos esse resgate histórico das ações legais e políticas, bem como das concepções e práticas em educação especial, é o de explicitarmos que a meta da universalização do ensino fundamental trouxe consigo a necessidade de incorporar à escola, grupos até então marginalizados de seu acesso, desse modo, implicando diretamente no debate e na inserção escolar de pessoas com deficiência.

Outro elemento é o de que, embora não tenha ocorrido uma superação do modelo da institucionalização para o da integração, e deste para o da inclusão, a difusão desse último conceito produziu resultados concretos, os quais estão expressos nos dados do censo escolar, podendo-se indicar alguns índices estatísticos para demonstrar a significativa ampliação do ensino a essa demanda reprimida do acesso à educação, seja em escolas do ensino regular, seja em escolas especiais.

Conforme dados do Censo escolar dispostos no site www.inep.gov.br, a partir do ano de 1998 os indicadores numéricos referente a matrícula de pessoas com deficiência são apresentados de forma melhor sistematizada, sendo exposto neste artigo somente o total geral de matrículas de alguns anos, os quais revelam a afirmação acima.

As quantidades de matriculas foram: em 1998 43.923, em 2001 81.344, em 2004 195.370, em 2006325.136 e em 2009 386.334. Esses dados nos permitem dizer que entre os anos de 1998 e 2009 houve um aumento de $779 \%$ nas matrículas, sendo que o debate em torno da qualidade do ensino, do número de concluintes da educação básica e da oferta dos serviços de apoio especializado não é objetivo deste artigo.

Antes de passarmos ao contexto da educação especial venezuelana, abordaremos, como o governo do presidente Lula, enfrentou às políticas neoliberais, uma vez que a preposição deste artigo vincula projeto neoliberal e educação especial. Nesse sentido, ressaltamos que Lula não promoveu uma guinada radical na gestão da política macroeconômica conduzida pelo ex-presidente FHC, sendo que algumas diretrizes do receituário neoliberal, como a reforma da previdência, foram revistas e tiveram continuidade em seu governo.

Apesar disto e de outras ações que não beneficiaram o conjunto dos trabalhadores, como os lucros exorbitantes dos bancos e a ascensão de uma burguesia interna, Lula efetivou políticas que, dado os princípios dos partidos que representam os interesses da elite dominante, nem de longe cogitariam executar, podendo se citar o aumento real do salário mínimo, mesmo sendo um baixo percentual; a retomada de maior controle do estado em áreas estratégicas, estancando as privatizações e uma política externa de ampliação de mercados das regiões sul-sul, particularmente com a América Latina.

Cabe destacar que a ida de muitos líderes dos movimentos sociais filiados ao PT, para o governo, possibilitou a implementação de algumas políticas sociais relevantes para estes, bem como a efetivação de políticas monetárias, como o pagamento da dívida com o FMI, o que possibilitou uma maior autonomia na condução da política econômica brasileira, além da visibilidade política a nível internacional destacando-se ainda a proximidade e o diálogo no plano político e comercial com o presidente Chávez, Evo Morales e outros governos da região, ações que demonstram que o presidente Lula não foi uma continuidade e nem se pautou pelo estrito receituário neoliberal de FHC. 


\section{A educação especial na Venezuela: contextualizando as reformas educacionais e explicitando alguns contrastes e as semelhanças dessa modalidade escolar}

Apresentado essa sumária conjuntura política, econômica e social do Brasil, na sequência do artigo, exporemos alguns aspectos da reforma educacional venezuelana, para em seguida, abordar a especificidade da política de educação especial neste país, buscando explicitar alguns contrastes e semelhanças em relação a essa modalidade educacional em âmbito brasileiro, assim como explicitar a atual conjuntura do neoliberalismo na Venezuela.

No que tange a reforma educacional venezuelana de 1990, assinalamos que, diferentemente do Brasil, onde uma das metas da reforma educacional neoliberal centrouse na universalização do ensino fundamental, na Venezuela, o foco da reforma esteve na descentralização e na privatização do ensino público, com isto, excluindo milhares de venezuelanos do acesso a educação.

Em relação a descentralização, Shiroma (2009), assim expressa:

[...] a apologia em prol da descentralização difundida pelas agências multilaterais que orientaram as reformas da década de 1990, ressaltam os aspectos da eficiência administrativa e da qualidade, mas ocultam os aspectos políticos de controle e de racionalização. Como argumentamos, a descentralização tem-se constituído em alternativa para diminuir os gastos públicos, compartilhando o financiamento da educação com as escolas e a sociedade civil, em especial via ações de responsabilidade social. (SHIROMA, 2009, p. 188).

Esse pilar do receituário neoliberal, não esteve à parte da conjuntura econômica e política vivenciada pelo país. Dessa forma, em linhas gerais, localizamos a origem e o papel da descentralização educacional e seus vínculos com a crise econômica expressa pela dívida externa venezuelana do início da década de 1980, a qual possibilitou o avanço das reformas neoliberais, que, dentre outros resultados, reduziu o tamanho e funções desse Estado, sob o argumento de torná-lo mais eficiente, transferindo, ou descentralizando, atribuições do governo central para outras instâncias, e restringindo gastos sociais, implicando diretamente a precarização da manutenção da escola pública.

A reforma de cunho economicista-mercadológica pôs em primeiro plano o controle dos gastos públicos e a sua minimização, deixando a cargo da sociedade a captação de outras fontes financeiras, o que levou à deterioração das escolas públicas e, por outro lado, corroborou para fortalecer o novo mercado, ou seja, a rede privada de ensino, dando destaque para aquelas de caráter confessional, que, segundo Ratjes (2009, p. 33 -34), "[...] intenta jugar un rol de sustituto del Estado en materia educativa. [...] la iglesia se convirtió en una entusiasta defensora de la descentralización como un mecanismo para capturar aparato escolar venezolano y defender los intereses de la elite venezolana".

Este cenário de desmantelamento do ensino público começou a ser alterado em 1999, quando Hugo Rafael Chávez Frías é eleito democraticamente presidente da República, desencadeando medidas significativas em direção a recuperação do caráter público da educação, medidas essas que ultrapassam o campo educacional e ampliam-se para outros setores sociais. As Transformações políticas, econômicas e sociais, as quais tem se defrontado diuturnamente com as críticas virulentas e ações políticas da burguesia rentista local, com o apoio de grande parte da burguesia e secretaria de estado estadunidense, que ao sentir-se ameaçada em seus interesses de classe dominante, repudia 
e tenta anular o governo chavista e as tentativas de colocar em prática os compromissos de campanha, a exemplo da necessária

Revolución Bolivariana, que terminaría con la corrupción y la traición en serie del bipartidismo venezolano. Se necesitaban reformas políticas y sociales radicales redistribución de la tierra y una nueva Constituciónpara una transformación estructural del sistema político y de la vida cotidiana del pueblo. (ALI, 2006, p. 74).

Com a refundação da República, definida na nova Carta Constitucional de 1999, que traz o caráter democrático, participativo e protagônico da população, necessitava-se de um novo homem republicano e o estabelecimento de uma nova Escola, não excludente, que contribuísse para o fortalecimento da identidade nacional e para o desenvolvimento endógeno do país. É nesse contexto que em 1999 é instituída, em caráter experimental, as "Escolas Bolivarianas"9 , as quais se constituíram em um sistema experimental de ensino que vigorou paralelamente à educação convencional.

Outra ação do Estado voltada para o campo educacional são as missões educativas inclusivas, as quais são parte das missões sociais ${ }^{10}$ criadas a partir do ano de 2003. As missões do campo da educação são destinadas a jovens e adultos que SE encontravam fora da idade escolar regular por terem interrompido os estudos em decorrência das condições materiais de existência, ou então, que sequer iniciaram o processo de escolarização. Essas missões educativas são denominadas de Missão "Robinson I, alfabetización; Misión Robinson II, prosecución al sexto grado; Misión Ribas, para culminar el bachillerato y Misión Sucre, con miras a municipalizar la educación superior". (VENEZUELA, 2004, p. $23)^{11}$.

Esse processo de reconstrução gradativa da educação pública tem seu ponto de culminância em agosto de 2009 com a aprovação da nova Lei Orgânica de Educação, que é a expressão da recuperação do caráter público da escola e da concretização do sistema educacional iniciado ainda em 1999, que deixou de ser paralelo para tornar-se oficial.

Essas ações políticas visaram a inclusão educacional de toda a população excluída do acesso a esse bem social, sendo que tais medidas tiveram repercussão na escolarização de pessoas com deficiência, afirmação que pode ser constatada nos índices de matrícula desse segmento social em institutos de educação especial, pois no ano de 1992/1993 havia o registro de 57.911 matrículas; em 1999/2000 já sob a gestão de Chávez, um total de 67.883; em 2003/2004 um total de 140.797; e no ano de 2006/2007 um quantitativo de $190.036^{12}$, representando uma clara ampliação do ensino, pois comparando 1999/2000 a 2006/2007 houve um aumento de 179,94\% nas matrículas, e se compararmos 2006/2007 com 1992/1993, a porcentagem aumenta para 228,15\%.

Da conjuntura atual para os marcos da trajetória histórica da educação especial venezuelana, assinalamos que da mesma forma que no Brasil, a educação das pessoas com deficiência esteve marcada pelas práticas da segregação e do cunho filantrópico, podendose destacar a criação da primeira instituição, de cunho privado, voltada ao atendimento desses sujeitos no ano de 1935, conforme lê-se:

[...] en respuesta a motivaciones personales de un grupo de padres y amigos de personas con problemas de audición y visión, surge así la Asociación Venezolana de Ciegos (1935) y el Instituto Venezolano de Ciegos y Sordomudos (1936) (VENEZUELA, 1997, p. 6). 
Semelhante ao Brasil, somente em 1975 com a criação da Direção Nacional de Educação Especial, é que o Estado venezuelano assume a escolarização de pessoas com deficiência como um direito social, incorporando-a no rol das políticas do Estado.

Um contraste que diferencia o histórico de ambos os países diz respeito à prática da institucionalização. Primeiramente, porque, nos documentos do Ministério da Educação venezuelano e em outras bibliografias analisadas, essa terminologia não consta e nem é considerada um modelo educacional. Em segundo, e que decorre do primeiro entendimento, é o de que, na Venezuela, nos anos de 1960/1970, não houve (ou ao menos não se encontraram registros nos documentos oficiais) manifestações no que concerne à desinstitucionalização das pessoas com deficiência. Pelo contrário,

[...] el Estado Venezolano a través del Ministerio de Educación, crea en 1974 el primer Instituto de Educación Especial para la atención de los ninos y jóvenes con Impedimentos Motores [...] no obstante, las acciones de dicho instituto se enmarcaban dentro de um modelo de atención más asistencial que educativo.(VENEZUELA, 1998, p.22).

A citação revela um movimento oposto, não de contestação, mas de abertura de novas instituições desse gênero, o que demonstra que os processos históricos não se desenvolvem tal qual nos diferentes contextos sociais, pois as particularidades, os embates políticos e a conjuntura de cada país produzem resultados distintos, mostrando também que o acesso à escola regular por parte de venezuelanos com deficiência, semelhante ao que ocorria no Brasil, ainda era restrito.

Inferimos que o não movimento pela desinstitucionalização pode ter sido um dos fatores que influenciou para que a educação de pessoas com deficiência na Venezuela ainda seja marcadamente ministrada em institutos de educação especial, conforme os indicadores numéricos apresentados anteriormente demonstraram.

Devemos destacar também que no país existe a orientação para a inserção em escolas do ensino regular, todavia tem sido sob a égide do conceito de integração, pois para essas escolas são encaminhados aqueles alunos que possuem condições para a ela se integrar, conforme se pode constatar no fragmento do documento do Ministério da Educação do Poder Popular:

[...] los educandos sordos y deficientes visuales son atendidos en Institutos de Educación Especial, con los programas disenados por el nivel de preescolar y de Educación Básica, hasta el $6^{\circ}$ grado. Al término de la programación, los alumnos son egresados al sistema educativo regular para que prosigan en los niveles correspondientes (VENEZUELA, 1997, p. 8).

Com exceção dos alunos com deficiência intelectual que permanecem nos institutos, os demais alunos com deficiência, desde que apresentem condições de acompanhar o ensino ministrado nas escolas regulares, após o $6^{\circ}$ grau podem ser integrados a estas instituições de ensino, ou antes mesmo, desde que seja do interesse da família, pois o currículo escolar é o mesmo.

A prática acima do governo venezuelano expressa bem a concepção de integração, conforme já abordado no histórico da educação especial no Brasil, pois segundo documento oficial, 
la integración como derecho, implica, gozar en pie de igualdad, de la educación, el trabajo, la recreación, la cultura y de los servicios sociales y al disfrute a los derechos económicos y sociales, así como también al cumplimiento de los deberes que el estado tiene asignado (VENEZUELA, 1997, p. 16).

Essa definição, em um primeiro momento, parece vir ao encontro dos princípios de inclusão que emergem no Brasil na década de 1990, uma vez que esse princípio apregoa o acesso a todos os espaços sociais em contraposição à integração, que, segundo a acepção corrente no Brasil, pressupunha a adaptação individual da pessoa com deficiência, para, só então, ser integrada socialmente. Refletindo, no entanto, com mais acuidade, no mesmo documento lemos:

Por otra parte el modelo para la integración social tiene un enfoque educativo, por cuanto se propicia un proceso de ajuste de las personas con necesidades especiales a los valores, exigencias y pautas de comportamientos de los grupos que conforman el medio ambiente social en el cual se desenvuelve [...]. Como proceso la integración social, se concibe como la adaptación de las respuestas del individuo a los requerimientos del medio y de la interacción de ambos. Es la secuencia por la que se van adquiriendo patrones conductuales que permiten la integración en la sociedad con la potencialidad de participar, interactuar y cooperar como miembro de un colectivo. (VENEZUELA, 1997, p. 16).

Com base nesta e outras referências, depreendemos que o conceito de integração, à primeira vista, pareceu possuir uma acepção diferente em relação à interpretação brasileira, contudo, ao incorporar a concepção de ajustamento e de adaptação, permanece emaranhado na normalização, princípio esse que, no Brasil, é criticado pelas pessoas com deficiência e por outros segmentos sociais, não por mera questão semântica, mas porque as palavras são carregadas de significados e expressam concepções das quais derivam práticas e atitudes pedagógicas e políticas. Dessa forma, assinalamos que os princípios da normalização e da integração não são contrastantes em relação ao conceito incorporado no Brasil, mas, sim, similares.

\section{Conclusão}

Face ao exposto, destacamos que na Venezuela na década de 1990, o conceito da integração permaneceu norteando a educação de pessoas com deficiência, sendo que no Brasil essa concepção muda em meados da primeira década do século XXI para inclusão educacional, com a difusão sistemática dos debates.

Sobre a inserção de pessoas com deficiência em escolas regulares, esclarecemos ainda que a Venezuela até meados de 2009, só havia sistematizado os índices de matrículas de pessoas com deficiência referente ao período letivo 2008/2009, demonstrando o quantitativo de 2.484 matrículas ${ }^{13}$ em salas de aula regulares, o que revela a baixa demanda em comparação as matrículas nos institutos de educação especial.

Neste país, o conceito de inclusão articulado à educação especial, legalmente, aparece somente no ano de 2007 quando é aprovado a Lei para as Pessoas com discapacidade. Sempre que esse conceito é referenciado, ao seu lado é citado também o conceito de integração, desse modo, ao serem empregados simultaneamente, expressam o entendimento de serem conceitos complementares e não conflitantes como ocorre na 
interpretação brasileira, em que o conceito inclusão possui uma acepção oposta em relação ao conceito de integração, ou seja, a integração é a inserção parcial, em que o indivíduo tem que se ajustar ou se adequar ao meio social. Já a inclusão pressupõe a adaptação dos espaços sociais, em que a sociedade deve ser modificada em vez de o indivíduo ter que se adaptar a um meio social não acessível.

Os estudos demonstraram que o conceito de inclusão em âmbito venezuelano passou a ser difundido a partir da gestão do presidente Hugo Chávez, conforme referenciamos na denominação das missões sociais inclusivas, e nessa perspectiva, ressaltamos que o conceito inclusão tem sido utilizado para se referir à população venezuelana alheia A todos os bens sociais e materiais. Já no Brasil, o conceito de inclusão dirigiu-se às minorias sociais, cimentando mais ainda a idéia de que a marginalidade social não está relacionada à condição de classe social, mas a questões particulares dos grupos minoritários, como raça, gênero, deficiência, etc.

Apresentado esse panorama geral que passou pela emergência do neoliberalismo nos países centrais e algumas particularidades desse pensamento político e econômico na América Latina, salientamos que no Brasil o neoliberalismo não foi superado, entretanto não existe uma sequência generalizada das heranças deixadas por FHC.

As reformas políticas e econômicas tiveram implicações de forma mediatizada no campo educacional. quando o MEC, centralizou a reforma educacional dos anos de 1990, à meta da universalização do ensino fundamental, essa orientação não partiu unilateralmente dos organismos internacionais, mas se somou às ações legais, políticas e reivindicativas, desde os anos de 1980, combatendo à evasão e à repetência escolar, numa "cruzada" em prol da democratização da escola pública, desse modo, antecedendo o evento de maior repercussão internacional que foi a Conferência mundial de educação para todos, realizada em JOMTIEN, 1990.

É neste contexto histórico, das reformas neoliberais, que o tema do acesso à escola regular, por parte de pessoas com deficiência ganha novas dimensões. Nesse sentido, cabe ainda destacar que a inegável ampliação dessas matrículas não foram apenas resultados das ações do Estado, mas foram também resultados de lutas históricas desse segmento social por acesso à educação. $\mathrm{O}$ que ocorreu no Brasil, se pode afirmar que não foi somente uma mudança conceitual, e nem tampouco uma política de inclusão restrita ao plano legal.

Já na Venezuela, os mecanismos do neoliberalismo estão sendo combatidos como política de estado, a exemplo da nacionalização de empresas e da expropriação de terras, bem como o custeio dos investimentos sociais estão sendo garantidos em grande parte, pela renda advinda da extração petroleira. Em relação à educação, esta situação começa a mudar substancialmente quando Chávez a partir de 1999, implementou ações como o impedimento de cobrança de taxa de matrícula em todos os níveis da rede pública, criando um sistema paralelo de educação permitindo o acesso a toda população em todos os níveis. Estas políticas repercutiram na educação de pessoas com deficiência, conforme os indicadores numéricos apresentados anteriormente demonstraram.

Por questões de delimitação do artigo, não iremos referenciar a legislação que garante o acesso á educação por parte de pessoas com deficiência, bem como os documentos internacionais que, da mesma forma que o Brasil, a Venezuela também se orienta, a exemplo da Declaração de Salamanca e da Convenção da ONU sobre os Direitos das Pessoas com Deficiência (2006). O contraste mais significativo de acordo com a análise, é da adoção da concepção de integração que ainda é predominante na Venezuela; educação que é marcadamente ministrada em institutos de educação especial, e somente da emergência do conceito de inclusão no âmago da política da educação especial a partir do ano de 2007. 
Sem filiar-se àqueles que defendem a inclusão condicional, ou seja, desde que a escola esteja preparada, entendemos que as providências, tanto no Brasil, como na Venezuela, só vem sendo tomadas em razão de que com a presença do aluno concreto, os problemas explodiram e a pressão organizada das associações e entidades tem tensionado o estado.

Por outro lado, entendemos também que algumas pessoas com deficiência possuem um grau de comprometimento tão severo que carecem do atendimento mais individualizado, e partindo do pressuposto de que a escola deve ser o espaço do conhecimento sistematizado e não somente um local para a convivência social, há que se refletir quanto a proposta de inclusão radical de todo o alunado da educação especial. Não só refletir sobre o contexto da escola regular, mas, também, refletir sobre a própria organização das escolas especiais, as quais mantêm, entre seu alunado, pessoas que possuem condições para acompanhar o ensino ministrado na escola comum, mas que dela foram excluídos por não se enquadrarem no perfil do aluno ideal.

Face ao exposto, sublinhamos os avanços adquiridos ao longo das décadas, entretanto chamamos a atenção para o quanto ainda é preciso conquistar, fazendo-as por meio da luta cotidiana dos movimentos em defesa do acesso à escola aos trabalhadores, sejam com deficiência ou não.

\section{Referências}

ALI, Tariq. Piratas del Caribe - el eje de la esperanza. Caracas: Ediciones Luxemburg, 2006.

BATISTA, Paulo Nogueira. O consenso de Washington: a visão neoliberal dos problemas latino-americanos. 3. ed. São Paulo: Paz e Terra, 2001.

BOITO, Armando Jr. A política neoliberal no Brasil. In: Política neoliberal e sindicalismo no Brasil. São Paulo: Xamã, 1999.

BRASIL. MINISTÉRIO DA EDUCAÇÃO. Secretaria de Educação Especial. Projeto Escola Viva, Visão Histórica. Série Amarela. Brasília, 2000.

BRASIL. Ministério da Educação . Instituto Nacional de Estudos e Pesquisas

Educacionais. Geografia da educação brasileira. Brasília, DF: MEC/INEP, 2001.

BUENO, José Geraldo Silveira. Educação especial brasileira: integração/segregação do aluno diferente. São Paulo: Educ, 1993.

CEPAL. Transformacion productiva con eqüidad: a tarea prioritaria del desarrollo de América Latina y el Caribe en los años noventa. Santiago, Chile, 1990.

CEPAL.UNESCO. Educação e conhecimento: eixo da transformação produtiva com equidade. Brasília: IPEA/CEPAL/INEP, 1995.

DELORS, Jacques. [et al.] (coord.). Educação: um tesouro a descobrir. Relatório para a UNESCO da Comissão Internacional sobre Educação para o século XXI. 10 ed. São Paulo: Cortez; Brasília, DF: MEC: UNESCO, 2006.

NAGEL, Lizia Helena. O estado e as políticas educacionais a partir dos anos 80. In; NOGUEIRA, F. M. G. Estado e políticas sociais no Brasil. Cascavel, PR: Edunioeste, 2001. 
NOGUEIRA, Francis Mary Guimarães. As orientações do Banco Mundial e as políticas educacionais atuais: a construção do consenso em torno da centralidade da educação básica. In: HIDALGO, Angela Maria; SILVA, lleizi Luciana Fiorelli (Org.). Educação e Estado: as mudanças nos sistemas de ensino do Brasil e do Paraná na década de 90. Londrina: Ed. UEL, 2001.

RATJES, Rubén Reinoso. Cambio y currículo en la escuela. Caracas: Centro Internacional Miranda, Ministerio de Educación Superior, 2009.

SHIROMA, Eneida Oto. Sentidos da descentralização nas propostas internacionais para a educação. In: BORGES, Liliam Faria Porto e MAZZUCO, Neiva Galina (Org.). Democracia e políticas sociais na América Latina. São Paulo: Xamã, 2009.

VENEZUELA. Ministério de Educación. Conceptualizacion y política de la atención educativa de las personas ciegas y deficientes visuales. Caracas, 1997.

VENEZUELA. Ministério de Educación. Conceptualizacion y politica de la atencion educativa de las personas con impedimentos fisicos. Caracas, 1998.

VENEZUELA. Ministério de Educación. conceptualización y política de la integración social de las personas con necesidades especiales: Programa de Integración Social. Caracas, 1997.

VENEZUELA. Ministerio de Educación y Deportes. La educación bolivariana: políticas, programas y acciones "cumpliendo las metas del milenio". Caracas, 2004. Disponível em: <www.oei.es/quipu/venezuela/index.html>. Acesso em: 28 abr 2010.

Notas:

\footnotetext{
${ }^{1}$ Professora da rede estadual de ensino da Secretaria de Estado da Educação do Paraná (SEED/PR). Mestre em educação pela Universidade Estadual do Oeste do Paraná (UNIOESTE). Membro do Grupo de Pesquisa em Políticas Sociais (GPPS) e do Grupo Estudos Marxistas em Educação. Integrante do Programa Institucional de Ações Relativas às Pessoas com Necessidades Especiais (PEE), da UNIOESTE, campus de Cascavel. E-mail: vandianabw@hotmail.com.

2 Doutora em Educação. Professora Associada da Universidade Estadual do Oeste do Paraná (Unioeste/Campus de Cascavel). Professora do Curso de Pedagogia e do Mestrado em Educação. Pesquisadora do Grupo de Pesquisa em Políticas Sociais (GPPS). E-mail: guimanog@ terra.com.br.

${ }^{3} \mathrm{O}$ conceito de centro e periferia foi apropriado do pensador argentino Raúl Prebisch. Entende-se que essa terminologia expressa melhor a condição dos países latino-americanos, históricos exportadores de matériaprima e importadores de tecnologia. Prefere-se essa denominação em lugar do conceito de países subdesenvolvidos e países desenvolvidos, pois, enquanto vigorar a atual divisão internacional do trabalho, os países pobres não chegarão a ser economias desenvolvidas tal qual os países centrais.

${ }^{4}$ Conhecimentos para o manejo das operações aritméticas básicas, a leitura e compreensão de um texto escrito, a comunicação escrita, a observação, descrição e análise crítica do entorno, a recepção e interpretação das mensagens dos meios de comunicação modernos e participação no desenho e execução de trabalhos em grupo.

${ }^{5}$ Para os organismos internacionais corresponde às séries iniciais, porém, no Brasil, foi traduzida como ensino fundamental, conforme os artigos 206, 211 e 214, pela obrigatoriedade apresentada na Constituição Federal de 1988

${ }^{6}$ Aprofundar estudos em GARCIA, Rosalba Maria Cardoso. "Políticas públicas de inclusão: uma análise no campo da educação especial brasileira". 2004. Tese (Programa de Pós-Graduação em Educação), Universidade Federal de Santa Catarina, Florianópolis-SC.
} 
${ }^{7}$ Sobre a tradução desse documento no Brasil ler: BUENO, José Geraldo Silveira. As políticas de inclusão escolar: uma prerrogativa da educação especial?. In: Deficiência e escolarização: novas perspectivas de análise. São Paulo: Junqueira \& Marin, 2008.

${ }^{8}$ No portal do MEC obtém-se a informação quanto aos equipamentos e aos materiais que estruturam as salas de recursos multifuncionais: As salas tipo 1, voltadas ao atendimento educacional especializado de alunos com deficiência, transtornos globais do desenvolvimento e superdotação, são constituídas de microcomputadores, monitores, fones de ouvido e microfones, scanner, impressora laser, teclado e colmeia, mouse e acionador de pressão, laptop, materiais e jogos pedagógicos acessíveis, software para comunicação alternativa, lupas manuais e lupa eletrônica, plano inclinado, mesas, cadeiras, armário, quadro melanínico. Já as salas tipo 2, específicas da área da deficiência visual, são constituídas dos recursos da sala tipo 1, acrescidos de outros recursos específicos para o atendimento de alunos com cegueira, tais como impressora Braille, máquina de datilografia Braille, reglete de mesa, punção, soroban, guia de assinatura, globo terrestre acessível, kit de desenho geométrico acessível, calculadora sonora, software para produção de desenhos gráficos e táteis.

9 A referência ao Libertador Simón Bolívar tem um profundo valor para os venezuelanos. Ressaltar o bolivariano remete-se a melhor das tradições e aos fundadores da nação.

${ }^{10}$ Essas missões tiveram início no ano de 2003, sendo políticas sociais financiadas com recursos advindos diretamente da renda petroleira.

11 Sobre as missões educativas ler: BORGES, Liliam Faria Porto e MAZZUCO, Neiva Galina (Org. Democracia e políticas sociais na América Latina. São Paulo: Xamã, 2009, pgs 105-121.

${ }^{12}$ Consultar: $\quad$ www.ine.gov.ve/condiciones/cuadro_educacion.asp?Tt=227-VI2\&cuadro=Educacion_227_ VI2\&xls $=227$ VI2

${ }^{13}$ Dos 24 Estados da Federação, em 8 destes não foi possível obter a quantidade de matrículas de pessoas com deficiência em classes comuns do ensino regular.

Recebido em agosto/2011

Aprovado em fevereiro/2012 